\title{
Prevention and Treatment of Atherosclerosis: The Use of Nutraceuticals and Functional Foods
}

\author{
Francesco Visioli and Andrea Poli
}

\section{Contents}

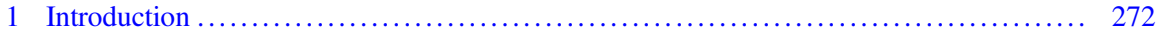

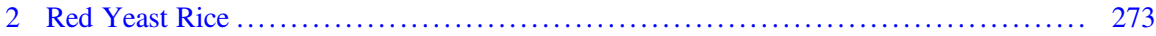

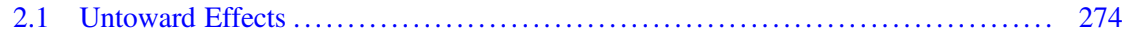

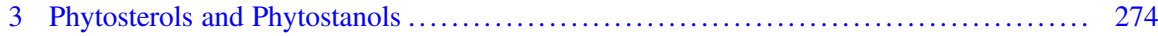

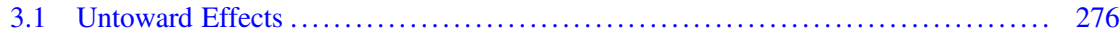

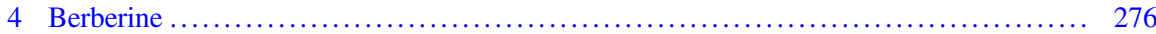

4.1 Untoward Effects .................................................. 277

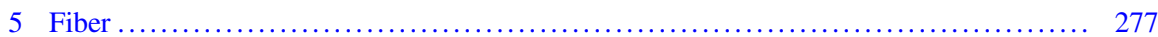

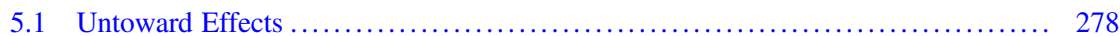

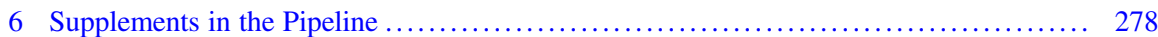

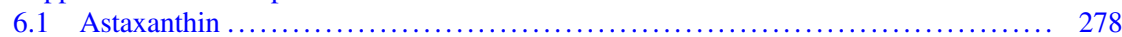

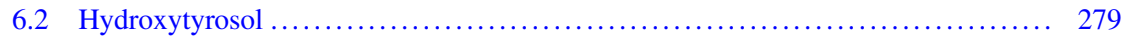

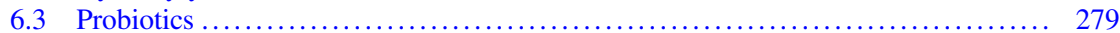

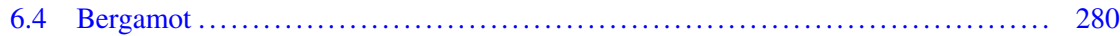

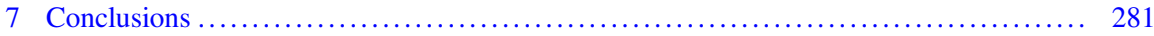

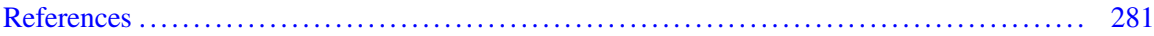

\section{Abstract}

Nutritional interventions are effective and - in theory - easy to implement primary and secondary prevention strategies that reduce several risk factors of atherosclerosis and cardiovascular disease (CVD). Yet, because of (a) the severe impact of CVD in terms of mortality, morbidity, quality of life, and economy, (b) the proved role of LDL plasma concentrations as the most critical risk factor,

F. Visioli

Department of Molecular Medicine, University of Padova, Padua, Italy

IMDEA-Food, CEI UAM+CSIC, Madrid, Spain
A. Poli $(\bowtie)$
Nutrition Foundation of Italy, Milan, Italy
e-mail: poli@nutrition-foundation.it

(C) The Author(s) 2019

A. von Eckardstein, C. J. Binder (eds.), Prevention and Treatment of Atherosclerosis,

Handbook of Experimental Pharmacology 270, https://doi.org/10.1007/164_2019_341 
and (c) the obstacles found both in terms of biological effects and compliance of the patient by an exclusively dietary intervention, food supplements or nutraceuticals are now valuable resources for physicians. As regards cholesterol control, several preparations are available in the market, and we will critically review them in this chapter.

\section{Keywords}

Atherosclerosis · Cardiovascular disease $\cdot$ Cholesterol $\cdot$ Diet $\cdot$ Functional foods · Nutraceuticals

\section{Introduction}

Atherosclerosis is multifactorial in nature and leads to various clinical forms of cardiovascular disease (CVD). Risk factors are manifold, but inflammation and elevated low-density lipoprotein (LDL) cholesterol are thought to be among the most important contributors (Alenghat and Davis 2019). In particular, Mendelian randomization studies and many intervention trials demonstrated that modifications of plasma LDL cholesterol concentrations are casually associated with cardiovascular risk (Ference 2015). As discussed in other parts of this book, variations of LDL predict cardiovascular risk in terms of amplitude and direction. Indeed, clinical trials have not yet allowed finding a lower limit of LDL concentrations to be achieved for optimal cardiovascular protection (Cholesterol Treatment Trialists et al. 2015).

Nutritional interventions are effective and - in theory - easy to implement primary and secondary prevention strategies that reduce several risk factors of atherosclerosis and CVD (Visioli and Poli 2019; Visioli et al. 2008). Focus on healthful food items, namely, fruit and vegetables and, hence, fiber, vitamins, (poly)phenols, and healthy fats (from extra virgin olive oil, vegetable oils, nuts, fatty fish) and low sodium improves diets and lessens CVD risk (Visioli and Hagen 2007; Visioli and Poli 2019). One notable example is the Mediterranean diet, which is associated with a significant improvement in health status and a significant reduction in overall mortality, as well as in morbidity and mortality from CVD and other major chronic diseases (Rees et al. 2019). Several systematic reviews of observational prospective studies have confirmed that greater adherence to such diet is associated with better health and greater longevity. Finally, the PREDIMED study provided important experimental proof of the cardioprotective properties of the Mediterranean diet (Martinez-Gonzalez et al. 2019). Consequently, physicians should pay particular attention to their patients' diets - even though curricular training is often suboptimal - and insist they preferentially adopt a plant-based regimen, enriched with fish and seafoods and with dairy products. Two limitations of dietary interventions are worth discussing. The first one is that the most commonly prescribed dietary and physical interventions have a limited $(-1.5$ to $5 \%)$ direct impact on LDL cholesterol levels, i.e., the foremost risk factor (Visioli and Poli 2019). The second and, perhaps, most important one is that extensive modifications of dietary habits are difficult to implement in real-life 
settings. It is worth reminding that humans are hardwired to maximize energy intake and limit expenditure (i.e., the "thrifty" genotype). New neurocognitive training methods are being investigated to lose weight and reduce sweets and fats consumption more effectively. However, translation of such results to clinical practice will require time.

Because of (a) the severe impact of CVD in terms of mortality, morbidity, quality of life, and economy, (b) the proved role of LDL plasma levels as the most critical risk factor among a large collection of others, and (c) the obstacles found both in terms of biological effects and compliance of the patient by an exclusively dietary intervention, food supplements or nutraceuticals deserve an in-depth analysis because they are valuable resources for physicians (Poli et al. 2018; Poli and Visioli 2019). As regards cholesterol control, several preparations are available in the market, and we will critically review them in this chapter.

\section{Red Yeast Rice}

The most popular supplement for cholesterol control is red yeast rice (RYR), which originates from the fermentation of rice performed by the fungus Monascus purpureus. Its denomination comes from color of the fermenting rice, Oryza sativa. With fermentation, a group of molecules identified as monacolin $\mathrm{K}$ is synthesized in both lactone $(\mathrm{K})$ and open ring acid forms $(\mathrm{Ka})$. Both molecules undergo interconversion in the body (Poli et al. 2013). Fermentations can take place in liquid and solid mediums. The latter is less efficient than the former, where the overall production of monacolin $\mathrm{K}$ is lower $(5-130 \mathrm{mg} / \mathrm{L})$ but is also relatively simpler (Vendruscolo et al. 2016). Some studies have shown that environmental factors affect the production of secondary metabolites by Monascus. Examples include nitrogen sources and glutamic acid, which improve (from 48.4 to $215.4 \mathrm{mg} / \mathrm{L}$ ) the production of monacolin K (Vendruscolo et al. 2016). Glutamic acid also increases the production of acetyl coenzyme A, which is a substrate for monacolin $\mathrm{K}$. This line of research stems from the similarities with lovastatin synthetic genes (LNKS) in Aspergillus. Indeed, often unbeknownst to the lay public, monacolin $\mathrm{K}$ is chemically identical to lovastatin and, thus, strongly inhibits HMG-CoA reductase. RYR also contains monacolins $\mathrm{J}, \mathrm{L}, \mathrm{X}$, and $\mathrm{M}$ that contribute to the inhibitory process to a lesser extent. A possible difference between RYR and lovastatin is their relative bioavailability: the former, according to a single study (Chen et al. 2013), is more bioavailable than the latter and, therefore, more effective on an mg-per-mg basis. Administered at doses of 3-10 mg/day, monacolin $\mathrm{K}$ reduces LDL cholesterol concentrations by 20-25\% (Fogacci et al. 2019; Li et al. 2014). Its effects on HDL cholesterol are negligible; triglyceridemia is mildly reduced unless plasma triglyceride concentrations are elevated, in which case the effects of RYR are stronger (Li et al. 2014; Sahebkar et al. 2016).

As with statins, probably due to their effects on LDL plasma levels, monacolin K improves endothelial function, with a number of favorable consequences: from systolic blood pressure reduction to plaque stabilization (Strazzullo et al. 2007). 


\subsection{Untoward Effects}

Even though RYR is perceived as "natural" and, hence, intrinsically safe, adverse effects of monacolin $\mathrm{K}$ are similar to those of statins, namely, lovastatin. These include elevated hepatic enzyme levels, gastrointestinal distress, and statinassociated myalgias (SAMs), i.e., muscle pain and weakness. Myositis (elevated creatinine phosphokinase [CPK] level) and rhabdomyolysis are more serious albeit highly infrequent complications of statin therapy (Stroes et al. 2015). Indeed, a recent review concluded that RYR is overall relatively tolerable and safe (Fogacci et al. 2019). Quite illogically, patients who experience statin-induced untoward effects often shift to RYR without telling their physicians. Some patients do experience a reduction of side effects, which could be explained by a "nocebo" effect. An alternative explanation for the higher tolerability of RYR products as compared with statins and observed in some studies (Becker et al. 2009) could be the lower doses of the active ingredient $(2.5-3 \mathrm{mg})$ that are usually found in supplements sold in Europe. Indeed, patients who are truly intolerant to statins are not many, and the safety profile of this class of drugs is excellent.

One often overlooked issue is that monacolin $\mathrm{K}$ can interact with other drugs, as in the case of statin therapy. RYR should not be co-administered with drugs containing itraconazole, ketoconazole, erythromycin, clarithromycin, telithromycin, HIV protease inhibitors, cyclosporine, nefazodone, green tea, and grapefruit juice ( $\geq 0.2 \mathrm{~L} /$ day) because monacolin $\mathrm{K}$ and statins are metabolized by cytochrome $\mathrm{P} 450$ and - in particular - by isoenzyme 3A4. Finally, the co-administration of statins and RYR should be avoided for pharmacodynamic reasons (both have the same mechanism of action) and comparable side effects (Cicero et al. 2017; Fogacci et al. 2019).

As a final cautionary note, the quality of commercial RYR-based products is rather heterogeneous (Gordon et al. 2010). The amount of active principle was found to vary by up to 100 times; recently, moreover, in an EFSA document, highly variable amounts of monacolin $\mathrm{K}$ in the lactone and in the open ring form were found in RYR-based products found on the market (EFSA 2018). The open ring form usually accounts for about one third of the total monacolins in RYR, whereas synthetic lovastatin is almost $100 \%$ lactone. Considering that open ring monacolin $\mathrm{K}$ levels as low as $0.1 \%$ were found in some samples, the possibility that synthetic monacolin is fraudulently sold as RYR cannot be excluded (Gordon et al. 2010).

Because nutraceuticals are not regulated as drugs, red rice supplements are not always subjected to strict adverse event monitoring programs. Physicians should make patients aware of potential risk factors related to the use of RYR nutraceuticals to ensure safety, lack of allergenic compounds, and potential untoward effects (Dujovne 2017).

\section{$3 \quad$ Phytosterols and Phytostanols}

Phytosterols (PS) are triterpenes that are usually classified as sterols or stanols, according to the presence or absence of a double bond in position 5. PS are found in free or esterified forms: free sterols are integral part of the cellular wall of plants, 
where they play important structural functions, whereas sterol esters represent storage products within the cell (Mamode Cassim et al. 2019). The only structural difference between sitosterol and cholesterol consists of an additional ethyl group present at position C-24 in sitosterol, which is probably at least in part responsible for its relatively poor intestinal absorption (Marangoni and Poli 2010).

There are more than 250 different PS molecules identified to date, $\beta$-sitosterol being the most abundant of them. Other plant sterols are present in vegetables and vegetable oils and include campesterol, stigmasterol, and dihydrobrassicasterol, at concentrations much lower than those of $\beta$-sitosterol; the saturated derivatives campestanol and sitostanol are found in almost negligible amounts in the vegetal kingdom (Marangoni and Poli 2010).

As mentioned, PS are mostly found in vegetables and derivatives such as vegetable oils; nuts, grains, and grain-derived products; and also sprouts, cabbages, cauliflowers, and green and black olives. Non-vegetable sources of PS include egg yolks, mammalian liver, and crustaceans. Commercially, PS are obtained from tall oil - which contains up to $80 \%$ of $\beta$-sitosterol - and the by-products of soybean oil production. Phytosterols are usually used as esterified forms to increase their solubility and allow for their incorporation into lipid-based foods (Marangoni and Poli 2010).

Considering that PS cannot be synthesized by humans, their circulating concentrations depend upon diet and absorption efficiency, as well as by its secretion in the gut by ABCG5-G5 transmembrane transporters. Depending on the type and amount of plant foods consumed, PS consumption and, in turn, PS blood concentrations vary within and between populations yet remain usually very low. Intervention studies report that higher phytosterols' intake as food supplements increases their circulating levels, while plant stanols supplementation decreases them. The absorption process is that of cholesterol and includes solubilized in mixed micelles, after the hydrolyzation of esters by a pancreatic ester hydroxylase. The specific carrier of cholesterol and PS is the Niemann-Pick C1-Like 1 (NPC1L1), i.e., the one that is specifically blocked by ezetimibe as discussed in other chapters of this book (Davis and Altmann 2009). Plasma levels of PS in humans are normally about $0.5 \%$ of those of cholesterol, because (1) the latter is synthesized in the liver, (2) PS is less efficiently absorbed by the small intestine, and (3) PS are rapidly excreted. Plant stanols concentrations in plasma are only $0.05 \%$ that of cholesterol (de Jong et al. 2003). Of note, PS play no known biological or functional role.

The main mechanisms responsible for the PS-induced reduction in cholesterol are their competition with cholesterol for incorporation into mixed micelles in the intestinal tract (Ras et al. 2014). As compared with cholesterol, PS are more readily hydrolyzed, and this process leads to a lower solubilization of cholesterol into micelles, which decreases their absorption and, in turn, increases fecal excretion of cholesterol and its metabolites. Co-crystallization of cholesterol and PS, leading to increased fecal excretion of cholesterol, may play a minor role.

Since PS absorbed from the gut are rapidly re-excreted in the gut lumen through the ATP-binding cassette transporters ABCG-5 and ABCG-8, located at the apical surface of the enterocyte, PS can have a rather long duration of action. This may 
explain why similar effects can be obtained by administering PS in a single dose or divided into three canonical meals (Plat et al. 2000). If this is true, the daily intake pattern would not affect PS efficacy, and the reduced incorporation of cholesterol into mixed micelles may only partially be responsible for the cholesterol-lowering effect of PS taken with meals. On the other hand, administration of PS without a meal is less effective $(-30 \%)$ than the same dose administered after a main meal (Doornbos et al. 2006). Patients need hence to be instructed to take PS after lunch or dinner.

In general, the cholesterol-lowering effect of PS is noticeable within few weeks and remains stable if supplementation is continuous (Ras et al. 2014). However, interruption of regular intakes reverses the effects of PS and brings cholesterol concentrations back to basal conditions. This is obvious, but patients are often satisfied with the results and stop taking PS without telling their physician. Finally, PS can be used as ad hoc preparations (beverages) or as functional ingredients of spreads, margarines, etc. (Ras et al. 2014).

This effect is additive to that of cholesterol synthesis inhibitors (statins), which compensatively tend to increase cholesterol absorption from the gut (Miettinen and Gylling 2003).

\subsection{Untoward Effects}

PS are safe, except for patients with homozygous sitosterolemia, who absorb between 15 and $60 \%$ of the ingested sitosterol compared to $<5 \%$ of normal subjects. The only proven untoward effect of PS is the reduction of circulating fat-soluble vitamins. Physicians should, therefore, reinforce the advice to consume five or more servings of fruit and vegetables per day, which effectively maintains carotenoid levels in the normal range.

\section{$4 \quad$ Berberine}

Berberine is the active component of barberry (Berberis vulgaris L. family Berberidaceae), which grows in Asia and Europe. Barberry is an integral part of Iranian traditional medicine (Dong et al. 2013). Among its many purported actions, hypotensive activity, gastric secretory stimulation, choleretic activity, increased tone of the digestive tract, anti-inflammatory activity, complement alternative pathway inhibition, delayed-type cutaneous hypersensitivity inhibition, antibacterial effects, antifungal effects, narcotic antagonist activity, and sedation have been suggested yet poorly investigated (Koppen et al. 2017). Of note, berberine is poorly bioavailable, i.e., $\sim 1 \%$, and pharmaceutical research is studying absorption enhancers and the use of nanoparticles or microemulsions to overcome this issue (Li et al. 2009; Liu et al. 2016).

Berberine is being mostly studied in Asian subjects and is being marketed in the West for its hypocholesterolemic activities. Indeed, some reviews indicate that 
berberine can lower plasma cholesterol to an extent similar to that of statins, i.e., 20-30\% (Johnston et al. 2017). This effect is greater in subjects with higher basal cholesterolemia and also depends on individual genetics.

In terms of mechanisms of action, berberine upregulates hepatic LDL receptor expression, likely by stabilizing LDL receptor mRNA through activation of extracellular signal-regulated kinase (ERK) pathways. Other studies suggest that berberine promotes LDL receptor expression through the inhibition of the proprotein PCSK9, which is also - likely - ERK-dependent (Dong et al. 2015). Another mechanism proposed for berberine is that it might interfere with intraluminal cholesterol micellarization, decreasing enterocyte cholesterol uptake, as shown in vitro in Caco-2 cells (Wang et al. 2014).

The effect of berberine on PCSK9 levels (which are compensatively increased during statin treatment) may explain the additive effect of berberine when administered with statins (Cicero et al. 2007). Nutraceuticals containing RYR and berberine are, in fact, quite popular.

The possibility that berberine also exerts a prebiotic effect, leading to a microbiota-mediated anti-atherosclerotic action, has recently been put forward based on animal studies (Zhu et al. 2018). Such effect would lead to reconsider the role of the amount of berberine unabsorbed from the gut.

\subsection{Untoward Effects}

Barberry per se is thought to be mildly toxic, but berberine is safe at therapeutic dosages. Gastrointestinal problems such as [chiefly] constipation, diarrhea, nausea, and abdominal distension are the most commonly reported side effects of berberine (Pirro et al. 2017). However, these effects diminish after reducing the dose of berberine. No other serious adverse events were reported in the trials that reported safety data, mainly obtained in Eastern countries. As with any other herbal treatment, herb-drug interactions should be carefully assessed in light of mutual cytochrome metabolism. Of note, repeated oral administration of berberine $(0.3 \mathrm{~g}$ three times daily) decreases CYP2D6, CYP2C9, and CYP3A4 activities in healthy subjects (Guo et al. 2012).

\section{$5 \quad$ Fiber}

An adequate intake of fiber has multiple beneficial effects on human health that transcend their mere actions on plasma cholesterol (Rubin 2019).

In terms of cholesterol control, some meta-analyses did quantify the actions of beta-glucan (a class of non-starch polysaccharides: $(1 \rightarrow 3)(1 \rightarrow 4)-\beta$-D-glucan, which are highly viscous nondigestible fiber). A daily beta-glucan dose of $3 \mathrm{~g}$ reduces LDL cholesterol by 5-6\%; no effects on other blood lipids have been reported (Cloetens et al. 2012). In addition to grains and cereals, namely, barley and oats, beta-glucan is available as ingredient of functional foods or as plain 
supplement. Glucomannan, psyllium (a predominantly gelling polysaccharide mixture), and chitosan are other cholesterol-lowering kinds of fiber.

The mechanisms of action of soluble fibers such as beta-glucan are still elusive (Ho et al. 2016). The most plausible hypothesis is that fiber increases fecal excretion of cholesterol, bile acids, and other dietary fats via formation of gels in the intestine. It is therefore advisable to tell patients to increase their intake of water during supplementation with fiber to facilitate the formation of such gel-like substances. The high molecular weight fraction of beta-glucan appears to be the most effective one.

A prebiotic effect cannot on the other hand be ruled out, leading to an increased synthesis of SCFA (especially propionate), which, after absorption, may act as an inhibitor of cholesterol synthesis in the liver (Reis et al. 2017). At high dosage, betaglucan also improves postprandial glycemic response (Ho et al. 2016).

\subsection{Untoward Effects}

The most frequently reported side effects of high fiber intake are gastrointestinal in nature and there is no tolerable upper limit for fiber. Precisely because fiber is nondigestible, it reaches the colon quite intact and undergoes fermentation by the microbiota. This can cause bloating and intestinal distress ranging from diarrhea to constipation (if water intake is inadequate). Co-administration of drugs also calls for caution because fiber can sequester active molecules and alter (usually decrease) bioavailability (Poli et al. 2018; Poli and Visioli 2019). Patients should be told to avoid such practice and to get used to fiber gradually.

\section{Supplements in the Pipeline}

After the policosanol fiasco, some molecules are being actively investigated for their potential role in hypercholesterolemia and dyslipidemia. We will briefly and critically review them here.

\subsection{Astaxanthin}

In light of its multiple biological actions, the xanthophyll carotenoid astaxanthin has been proposed as a suitable preventive and therapeutic agent in cardiovascular disease (Kishimoto et al. 2016). Astaxanthin exhibited lipid-lowering activity in laboratory mice supplemented diet with $>0.03 \%$ of astaxanthin from $H$. pluvialis for 12 weeks, namely, lowering plasma TG concentrations. No significant differences in plasma TC and HDL-C concentrations between the control and treatment groups were reported (Yang et al. 2014). In a murine model of metabolic syndrome, a significant increase in HDL-C and a significant decrease of plasma TG levels and nonesterified fatty acids were induced by astaxanthin given at $50 \mathrm{mg} / \mathrm{kg} /$ day for 
22 weeks. Moreover, astaxanthin decreased the size of the fat cells of white adipose tissue. In addition, lower adiponectin concentrations were recorded in the serum of obese, insulin-resistant type 2 diabetic rodents and humans, indicating a possible correlation between adiponectin concentrations and insulin resistance and fat accumulation (Stern et al. 2016).

The purported hypolipidemic effects of astaxanthin require further investigation, and its mechanisms of action are still unclear (Visioli and Artaria 2017). A metaanalysis by Ursoniu et al. (2015) indeed concluded that astaxanthin does not exert any significant effect in terms of plasma lipid profile. Of note, astaxanthin sourced from the microalgae $H$. pluvialis is the only one currently authorized for direct human consumption (Visioli and Artaria 2017), and consumers should be aware of possible contaminations with other sources of this carotenoid (as in the case of monacolin K). Further ad hoc investigations will eventually allow (or not) the addition of astaxanthin to the array of nutraceuticals for cholesterol control.

\subsection{Hydroxytyrosol}

Hydroxytyrosol (HT)'s activities on cholesterol and TGs are still equivocal and, likely, quantitatively irrelevant (Crespo et al. 2018). However, it is worth noting that HT has manifold biological actions that might prove useful to hypercholesterolemic patients (Tome-Carneiro and Visioli 2016). Such activities include thrombogenic potential reduction, anti-inflammatory actions, and inhibition of LDL oxidation as per an EFSA-authorized health claim (Crespo et al. 2018). Despite the hype, this last activity is of dubious relevance to human physiology, also in light of the antioxidant therapy debacle and the lack of appropriate and validated tests (Visioli et al. 2018). In any case, HT is being actively studied for its molecular actions, and accumulated data are strongly suggestive of its cardioprotective actions, regardless of the effects on cholesterol (Visioli et al. 2018).

\subsection{Probiotics}

Despite the lack of strong scientific evidence, the use of probiotics is increasing, and this includes the cardiovascular arena (Cavalcanti Neto et al. 2018).

Several possible mechanisms for cholesterol's intestinal removal by probiotics have been proposed (Shimizu et al. 2015). Examples include binding of cholesterol to cell surface (in a fashion similar to that of PS of fiber), uptake of cholesterol by growing cells, deconjugation of bile via bile salt hydrolase and subsequent coprecipitation of cholesterol, and some unclear physiological actions of shortchain fatty acid fermentation (Reis et al. 2017).

Prebiotics such as inulin and fructooligosaccharides are soluble, indigestible, viscous, and fermentable compounds that might play hypocholesterolemic actions either by decreasing cholesterol absorption and increasing its fecal excretion (similar to fiber as discussed above) or via production of short-chain fatty acids after their 
fermentation by the microbiota. The use of synbiotics is, thus, often advocated for cholesterol control (Mahboobi et al. 2018).

We would like to make the readers aware of the fact that no health claim has been awarded for any probiotic strain as related to lowering cholesterol. The use of probiotics rests on theoretical grounds and some in vitro experiments. Future, wellcontrolled and large-scale human experiments will eventually support the use of probiotics in hypercholesterolemic patients.

\subsection{Bergamot}

Bergamot is a citrus fruit belonging to the genus Citrus, endemic to the Southern coastal area of Calabria (Italy). The derivatives of bergamot traditionally come from the essential oil contained in the peel and were obtained manually, by pressing. This process is now industrialized and allows the marketing of large quantities of preparations. The main use of bergamot essential oil (after de-furocumarinization) is still in the food industry (for the flavoring of Earl Grey tea) and in the perfumery field, for its particular aroma. From a biomedical viewpoint, the most interesting phytochemical components of bergamot are the (poly)phenolic molecules present in its juice (commercially called bergamot polyphenolic fraction (BPF)) and the volatile terpenes that characterize the essential oil (Nauman and Johnson 2019).

The BPF exercises various actions on glycolipid metabolism, including the ability to reduce the hepatic accumulation of triglycerides, the partial inhibition of their synthesis, and the ability to inhibit the action of acyl-CoA cholesterol acyltransferase (ACAT) (Janda et al. 2016). The result is a lower production of apoB-containing lipoproteins. More recently, it has also been observed that the BPF is able to efficiently inhibit the pancreatic cholesterol ester hydrolase ( $\mathrm{pCEH})$, which leads to a reduction in the absorption of dietary cholesterol (Giglio et al. 2016).

Furthermore, the (poly)phenolic components of bergamot activate AMPK. AMPK is an important regulator of the metabolic pathways involved in the production of ATP in mammalian cells and acts as a sensor of AMP/ATP levels. The intracellular AMP increases when the energy state is low and binds to the AMPK to allow activation.

Finally, it is important to emphasize that the BPF can act directly as an HMG-CoA reductase inhibitor, thus exerting effects potentially similar to those of statins (Leopoldini et al. 2010).

In randomized, double-blind studies carried out in hyperlipemic and type 2 diabetes subjects, a remarkable effect of BPF was found in terms of reducing fasting blood glucose, LDL cholesterol, and triglycerides and increasing HDL cholesterol (Cai et al. 2017; Toth et al. 2015). In another study, a lecithin formulation (to increase bioavailability) of BPF, already successfully tested at the preclinical level, was used at a daily dose of $1,000 \mathrm{mg}$ (corresponding to $400 \mathrm{mg}$ of BPF) (Mollace et al. 2019). Lipid-lowering and hypoglycemic effects similar to those of BPF at a dose of $1,300 \mathrm{mg}$ were recorded (Mollace et al. 2019). All these data must be, obviously, 
confirmed in other randomized clinical trials before the BPF can become part of the therapeutic armamentarium (Nauman and Johnson 2019).

\section{Conclusions}

The decision to recommend a functional food or supplement/nutraceutical is integral part of the therapy and should be taken by physicians, not patients or other health professionals. This process includes the decision of which supplement to prescribe and at which dose, as well as timely checkups in order to monitor the safety and efficacy of treatment.

Furthermore, physicians should instruct patients on the importance and role of supplements, removing the "natural" halo with which they are often marketed. Because most supplements are not reimbursed by national healthcare systems, physicians should make sure their patients can sustain costs over time, considering that such treatment is often lengthy and in theory lifelong.

In this framework, some supplements and functional foods can effectively reduce plasma LDL cholesterol levels by 5-25\%, either alone or in combination. As with pharmacological treatments, physicians must monitor the use of nutraceuticals and verify their regular use, their effects on lipid profile, as well as the eventual occurrence of untoward effects, many of which are typical of classic drugs. Should cardiovascular risk worsen remarkably, inclusion of ethical drugs is mandatory.

In conclusion, many effective and relatively safe nutraceuticals and functional foods are available and are backed by solid scientific evidence. Their use in cholesterol control and dyslipidemia is warranted in the frame of a comprehensive therapeutic strategy.

Acknowledgments Supported in part by POR FESR 3S4H.

Conflict of Interest None.

\section{References}

Alenghat FJ, Davis AM (2019) Management of Blood Cholesterol. JAMA 321:800-801

Becker DJ, Gordon RY, Halbert SC, French B, Morris PB, Rader DJ (2009) Red yeast rice for dyslipidemia in statin-intolerant patients: a randomized trial. Ann Intern Med 150:830-839, W147-9

Cai Y, Xing G, Shen T, Zhang S, Rao J, Shi R (2017) Effects of 12-week supplementation of Citrus bergamia extracts-based formulation CitriCholess on cholesterol and body weight in older adults with dyslipidemia: a randomized, double-blind, placebo-controlled trial. Lipids Health Dis 16:251

Cavalcanti Neto MP, Aquino JS, Romao da Silva LF, de Oliveira Silva R, Guimaraes KSL, de Oliveira Y, de Souza EL, Magnani M, Vidal H, de Brito Alves JL (2018) Gut microbiota and probiotics intervention: a potential therapeutic target for management of cardiometabolic disorders and chronic kidney disease? Pharmacol Res 130:152-163

Chen CH, Yang JC, Uang YS, Lin CJ (2013) Improved dissolution rate and oral bioavailability of lovastatin in red yeast rice products. Int J Pharm 444:18-24 
Cholesterol Treatment Trialists C, Fulcher J, O’Connell R, Voysey M, Emberson J, Blackwell L, Mihaylova B, Simes J, Collins R, Kirby A, Colhoun H, Braunwald E, La Rosa J, Pedersen TR, Tonkin A, Davis B, Sleight P, Franzosi MG, Baigent C, Keech A (2015) Efficacy and safety of LDL-lowering therapy among men and women: meta-analysis of individual data from 174,000 participants in 27 randomised trials. Lancet 385:1397-1405

Cicero AF, Rovati LC, Setnikar I (2007) Eulipidemic effects of berberine administered alone or in combination with other natural cholesterol-lowering agents. A single-blind clinical investigation. Arzneimittelforschung 57:26-30

Cicero AFG, Colletti A, Bajraktari G, Descamps O, Djuric DM, Ezhov M, Fras Z, Katsiki N, Langlois M, Latkovskis G, Panagiotakos DB, Paragh G, Mikhailidis DP, Mitchenko O, Paulweber B, Pella D, Pitsavos C, Reiner Z, Ray KK, Rizzo M, Sahebkar A, Serban MC, Sperling LS, Toth PP, Vinereanu D, Vrablik M, Wong ND, Banach M (2017) Lipid-lowering nutraceuticals in clinical practice: position paper from an International Lipid Expert Panel. Nutr Rev 75:731-767

Cloetens L, Ulmius M, Johansson-Persson A, Akesson B, Onning G (2012) Role of dietary betaglucans in the prevention of the metabolic syndrome. Nutr Rev 70:444-458

Crespo MC, Tome-Carneiro J, Davalos A, Visioli F (2018) Pharma-nutritional properties of olive oil phenols. Transfer of new findings to human nutrition. Foods 7

Davis HR Jr, Altmann SW (2009) Niemann-Pick C1 Like 1 (NPC1L1) an intestinal sterol transporter. Biochim Biophys Acta 1791:679-683

de Jong A, Plat J, Mensink RP (2003) Metabolic effects of plant sterols and stanols (review). J Nutr Biochem 14:362-369

Dong H, Zhao Y, Zhao L, Lu F (2013) The effects of berberine on blood lipids: a systemic review and meta-analysis of randomized controlled trials. Planta Med 79:437-446

Dong B, Li H, Singh AB, Cao A, Liu J (2015) Inhibition of PCSK9 transcription by berberine involves down-regulation of hepatic HNF1alpha protein expression through the ubiquitinproteasome degradation pathway. J Biol Chem 290:4047-4058

Doornbos AM, Meynen EM, Duchateau GS, van der Knaap HC, Trautwein EA (2006) Intake occasion affects the serum cholesterol lowering of a plant sterol-enriched single-dose yoghurt drink in mildly hypercholesterolaemic subjects. Eur J Clin Nutr 60:325-333

Dujovne CA (2017) Red yeast rice preparations: are they suitable substitutions for statins? Am J Med 130:1148-1150

EFSA Panel on Food Additives and Sources Added to Food (2018) Scientific opinion on the safety of monacolins in red yeast rice. EFSA J 16:5368

Ference BA (2015) Mendelian randomization studies: using naturally randomized genetic data to fill evidence gaps. Curr Opin Lipidol 26:566-571

Fogacci F, Banach M, Mikhailidis DP, Bruckert E, Toth PP, Watts GF, Reiner Z, Mancini J, Rizzo M, Mitchenko O, Pella D, Fras Z, Sahebkar A, Vrablik M, Cicero AFG, Lipid, Blood Pressure Meta-analysis Collaboration Group the International Lipid Expert P (2019) Safety of red yeast rice supplementation: a systematic review and meta-analysis of randomized controlled trials. Pharmacol Res 143:1-16

Giglio RV, Patti AM, Nikolic D, Li Volti G, Al-Rasadi K, Katsiki N, Mikhailidis DP, Montalto G, Ivanova E, Orekhov AN, Rizzo M (2016) The effect of bergamot on dyslipidemia. Phytomedicine 23:1175-1181

Gordon RY, Cooperman T, Obermeyer W, Becker DJ (2010) Marked variability of monacolin levels in commercial red yeast rice products: buyer beware! Arch Intern Med 170:1722-1727

Guo Y, Chen Y, Tan ZR, Klaassen CD, Zhou HH (2012) Repeated administration of berberine inhibits cytochromes P450 in humans. Eur J Clin Pharmacol 68:213-217

Ho HV, Sievenpiper JL, Zurbau A, Blanco Mejia S, Jovanovski E, Au-Yeung F, Jenkins AL, Vuksan V (2016) The effect of oat beta-glucan on LDL-cholesterol, non-HDL-cholesterol and apoB for CVD risk reduction: a systematic review and meta-analysis of randomised-controlled trials. Br J Nutr 116:1369-1382 
Janda E, Lascala A, Martino C, Ragusa S, Nucera S, Walker R, Gratteri S, Mollace V (2016) Molecular mechanisms of lipid- and glucose-lowering activities of bergamot flavonoids. PharmaNutrition 4:S8-S18

Johnston TP, Korolenko TA, Pirro M, Sahebkar A (2017) Preventing cardiovascular heart disease: promising nutraceutical and non-nutraceutical treatments for cholesterol management. Pharmacol Res 120:219-225

Kishimoto Y, Yoshida H, Kondo K (2016) Potential anti-atherosclerotic properties of astaxanthin. Mar Drugs 14

Koppen LM, Whitaker A, Rosene A, Beckett RD (2017) Efficacy of berberine alone and in combination for the treatment of hyperlipidemia: a systematic review. J Evid Based Complementary Altern Med 22:956-968

Leopoldini M, Malaj N, Toscano M, Sindona G, Russo N (2010) On the inhibitor effects of bergamot juice flavonoids binding to the 3-hydroxy-3-methylglutaryl-CoA reductase (HMGR) enzyme. J Agric Food Chem 58:10768-10773

Li YH, Yang P, Kong WJ, Wang YX, Hu CQ, Zuo ZY, Wang YM, Gao H, Gao LM, Feng YC, Du NN, Liu Y, Song DQ, Jiang JD (2009) Berberine analogues as a novel class of the low-densitylipoprotein receptor up-regulators: synthesis, structure-activity relationships, and cholesterollowering efficacy. J Med Chem 52:492-501

Li Y, Jiang L, Jia Z, Xin W, Yang S, Yang Q, Wang L (2014) A meta-analysis of red yeast rice: an effective and relatively safe alternative approach for dyslipidemia. PLoS One 9:e98611

Liu CS, Zheng YR, Zhang YF, Long XY (2016) Research progress on berberine with a special focus on its oral bioavailability. Fitoterapia 109:274-282

Mahboobi S, Rahimi F, Jafarnejad S (2018) Effects of prebiotic and synbiotic supplementation on glycaemia and lipid profile in type 2 diabetes: a meta-analysis of randomized controlled trials. Adv Pharm Bull 8:565-574

Mamode Cassim A, Gouguet P, Gronnier J, Laurent N, Germain V, Grison M, Boutte Y, GerbeauPissot P, Simon-Plas F, Mongrand S (2019) Plant lipids: key players of plasma membrane organization and function. Prog Lipid Res 73:1-27

Marangoni F, Poli A (2010) Phytosterols and cardiovascular health. Pharmacol Res 61:193-199

Martinez-Gonzalez MA, Gea A, Ruiz-Canela M (2019) The Mediterranean diet and cardiovascular health. Circ Res 124:779-798

Miettinen TA, Gylling H (2003) Synthesis and absorption markers of cholesterol in serum and lipoproteins during a large dose of statin treatment. Eur J Clin Investig 33:976-982

Mollace V, Scicchitano M, Paone S, Casale F, Calandruccio C, Gliozzi M, Musolino V, Carresi C, Maiuolo J, Nucera S, Riva A, Allegrini P, Ronchi M, Petrangolini G, Bombardelli E (2019) Hypoglycemic and hypolipemic effects of a new lecithin formulation of bergamot polyphenolic fraction: a double blind, randomized, placebo-controlled study. Endocr Metab Immune Disord Drug Targets 19:136-143

Nauman MC, Johnson JJ (2019) Clinical application of bergamot (Citrus bergamia) for reducing high cholesterol and cardiovascular disease markers. Integr Food Nutr Metab 6

Pirro M, Vetrani C, Bianchi C, Mannarino MR, Bernini F, Rivellese AA (2017) Joint position statement on "nutraceuticals for the treatment of hypercholesterolemia" of the Italian Society of Diabetology (SID) and of the Italian Society for the Study of Arteriosclerosis (SISA). Nutr Metab Cardiovasc Dis 27:2-17

Plat J, van Onselen EN, van Heugten MM, Mensink RP (2000) Effects on serum lipids, lipoproteins and fat soluble antioxidant concentrations of consumption frequency of margarines and shortenings enriched with plant stanol esters. Eur J Clin Nutr 54:671-677

Poli A, Visioli F (2019) Pharmacology of nutraceuticals with lipid lowering properties. High Blood Press Cardiovasc Prev 26:113-118

Poli A, Marangoni F, Avogaro A, Barba G, Bellentani S, Bucci M, Cambieri R, Catapano AL, Costanzo S, Cricelli C, de Gaetano G, Di Castelnuovo A, Faggiano P, Fattirolli F, Fontana L, Forlani G, Frattini S, Giacco R, La Vecchia C, Lazzaretto L, Loffredo L, Lucchin L, Marelli G, Marrocco W, Minisola S, Musicco M, Novo S, Nozzoli C, Pelucchi C, Perri L, Pieralli F, Rizzoni D, Sterzi R, Vettor R, Violi F, Visioli F (2013) Moderate alcohol use and health: a consensus document. Nutr Metab Cardiovasc Dis 23:487-504 
Poli A, Barbagallo CM, Cicero AFG, Corsini A, Manzato E, Trimarco B, Bernini F, Visioli F, Bianchi A, Canzone G, Crescini C, de Kreutzenberg S, Ferrara N, Gambacciani M, Ghiselli A, Lubrano C, Marelli G, Marrocco W, Montemurro V, Parretti D, Pedretti R, Perticone F, Stella R, Marangoni F (2018) Nutraceuticals and functional foods for the control of plasma cholesterol levels. An intersociety position paper. Pharmacol Res 134:51-60

Ras RT, Geleijnse JM, Trautwein EA (2014) LDL-cholesterol-lowering effect of plant sterols and stanols across different dose ranges: a meta-analysis of randomised controlled studies. Br J Nutr 112:214-219

Rees K, Takeda A, Martin N, Ellis L, Wijesekara D, Vepa A, Das A, Hartley L, Stranges S (2019) Mediterranean-style diet for the primary and secondary prevention of cardiovascular disease. Cochrane Database Syst Rev 3:CD009825

Reis SA, Conceicao LL, Rosa DD, Siqueira NP, Peluzio MCG (2017) Mechanisms responsible for the hypocholesterolaemic effect of regular consumption of probiotics. Nutr Res Rev 30:36-49

Rubin R (2019) High-fiber diet might protect against range of conditions. JAMA 321:1653-1655

Sahebkar A, Serban MC, Gluba-Brzozka A, Mikhailidis DP, Cicero AF, Rysz J, Banach M (2016) Lipid-modifying effects of nutraceuticals: an evidence-based approach. Nutrition 32:1179-1192

Shimizu M, Hashiguchi M, Shiga T, Tamura HO, Mochizuki M (2015) Meta-analysis: effects of probiotic supplementation on lipid profiles in normal to mildly hypercholesterolemic individuals. PLoS One 10:e0139795

Stern JH, Rutkowski JM, Scherer PE (2016) Adiponectin, leptin, and fatty acids in the maintenance of metabolic homeostasis through adipose tissue crosstalk. Cell Metab 23:770-784

Strazzullo P, Kerry SM, Barbato A, Versiero M, D’Elia L, Cappuccio FP (2007) Do statins reduce blood pressure?: a meta-analysis of randomized, controlled trials. Hypertension 49:792-798

Stroes ES, Thompson PD, Corsini A, Vladutiu GD, Raal FJ, Ray KK, Roden M, Stein E, Tokgozoglu L, Nordestgaard BG, Bruckert E, De Backer G, Krauss RM, Laufs U, Santos RD, Hegele RA, Hovingh GK, Leiter LA, Mach F, Marz W, Newman CB, Wiklund O, Jacobson TA, Catapano AL, Chapman MJ, Ginsberg HN, European Atherosclerosis Society Consensus P (2015) Statin-associated muscle symptoms: impact on statin therapy-European Atherosclerosis Society Consensus Panel statement on assessment, aetiology and management. Eur Heart J 36:1012-1022

Tome-Carneiro J, Visioli F (2016) Polyphenol-based nutraceuticals for the prevention and treatment of cardiovascular disease: review of human evidence. Phytomedicine 23:1145-1174

Toth PP, Patti AM, Nikolic D, Giglio RV, Castellino G, Biancucci T, Geraci F, David S, Montalto G, Rizvi A, Rizzo M (2015) Bergamot reduces plasma lipids, atherogenic small dense LDL, and subclinical atherosclerosis in subjects with moderate hypercholesterolemia: a 6 months prospective study. Front Pharmacol 6:299

Ursoniu S, Sahebkar A, Serban MC, Banach M (2015) Lipid profile and glucose changes after supplementation with astaxanthin: a systematic review and meta-analysis of randomized controlled trials. Arch Med Sci 11:253-266

Vendruscolo F, Meinicke Buhler RM, Cesar de Carvalho J, de Oliveira D, Moritz DE, Schmidell W, Ninow JL (2016) Monascus: a reality on the production and application of microbial pigments. Appl Biochem Biotechnol 178:211-223

Visioli F, Artaria C (2017) Astaxanthin in cardiovascular health and disease: mechanisms of action, therapeutic merits, and knowledge gaps. Food Funct 8:39-63

Visioli F, Hagen TM (2007) Nutritional strategies for healthy cardiovascular aging: focus on micronutrients. Pharmacol Res 55:199-206

Visioli F, Poli A (2019) Dietary advice to cardiovascular patients. A brief update for physicians. Monaldi Arch Chest Dis 89

Visioli F, Poli A, Richard D, Paoletti R (2008) Modulation of inflammation by nutritional interventions. Curr Atheroscler Rep 10:451-453

Visioli F, Franco M, Toledo E, Luchsinger J, Willett WC, Hu FB, Martinez-Gonzalez MA (2018) Olive oil and prevention of chronic diseases: summary of an international conference. Nutr Metab Cardiovasc Dis 28:649-656 
Wang Y, Yi X, Ghanam K, Zhang S, Zhao T, Zhu X (2014) Berberine decreases cholesterol levels in rats through multiple mechanisms, including inhibition of cholesterol absorption. Metabolism 63:1167-1177

Yang Y, Pham TX, Wegner CJ, Kim B, Ku CS, Park YK, Lee JY (2014) Astaxanthin lowers plasma TAG concentrations and increases hepatic antioxidant gene expression in diet-induced obesity mice. Br J Nutr 112:1797-1804

Zhu L, Zhang D, Zhu H, Zhu J, Weng S, Dong L, Liu T, Hu Y, Shen X (2018) Berberine treatment increases Akkermansia in the gut and improves high-fat diet-induced atherosclerosis in Apoe(-/-) mice. Atherosclerosis 268:117-126

Open Access This chapter is licensed under the terms of the Creative Commons Attribution 4.0 International License (http://creativecommons.org/licenses/by/4.0/), which permits use, sharing, adaptation, distribution and reproduction in any medium or format, as long as you give appropriate credit to the original author(s) and the source, provide a link to the Creative Commons licence and indicate if changes were made.

The images or other third party material in this chapter are included in the chapter's Creative Commons licence, unless indicated otherwise in a credit line to the material. If material is not included in the chapter's Creative Commons licence and your intended use is not permitted by statutory regulation or exceeds the permitted use, you will need to obtain permission directly from the copyright holder. 